\title{
A Study on Curriculum Evaluation Methods in Higher Education
}

\author{
Yingjie $\mathrm{FU}^{1, \mathrm{a}}$ \\ ${ }^{1}$ Department of Teaching Affairs, Jilin Agricultural University, 130118, Changchun, China \\ aemail:jlaufyj@126.com
}

Keywords: Course evaluation; Problem; Strategy

\begin{abstract}
Course evaluation is an important part of the teaching quality monitor and support system in higher learning institutes. This paper analyzes the current problems associated with course evaluation and discusses the role of course evaluation in the cultivation of talents. Finally some suggestions are put forward as to how to reform course evaluation method.
\end{abstract}

\section{Introduction}

Quality is the lifeblood of education, and curriculum is the carrier of education. Curriculum evaluation in higher education is an effective measure to ensure the quality of higher education as well as an important way to promote reflection and innovation on curriculum. During higher education activities, the quality of curriculum is directly related to the quality and level of talent training. Therefore, the importance of curriculum evaluation in higher education has become increasingly obvious, which makes the study on curriculum evaluation inevitable.

\section{Existing problems in curriculum evaluation}

Evaluating curriculum is equivalent to evaluating teachers

It is common that evaluating curriculum is equivalent to evaluating teachers in colleges and universities. It turns the object of curriculum evaluation into teachers rather than curriculum itself, which is presented as follows:

In terms of curriculum evaluation index system, most colleges and universities start from the perspective of teaching level of teachers design the index framework including teaching preparation, teaching attitude, teaching content, teaching organization, teaching effect and so on by aiming the object of evaluation at teachers themselves ${ }^{[1]}$.

In terms of the use of evaluation results, most colleges and universities will examine both the scores and teachers evaluated. As a result, the teaching level of teachers is highly correlated with the construction quality of curriculum. A teacher with higher teaching level and stronger ability will own a higher level in curriculum construction ${ }^{[2]}$. Meanwhile, the teaching ability of teachers is equivalent to their curriculum construction ability in practical application. Thus, the use of evaluation results is pointed at teachers.

Evaluation of classroom teaching is equivalent to curriculum evaluation

From the practical perspective of curriculum evaluation in colleges and universities, the focus may rise to experiential summary materials. It is common that evaluation of classroom teaching is equivalent to curriculum evaluation, which is mainly presented as follows: evaluate preparation, organization and implementation of classroom teaching as a whole, regard the partial as a whole, and especially regard organization ability and teaching level of classroom teaching as the whole of curriculum $^{[3]}$. Evaluation of classroom teaching is one of the important contents of curriculum evaluation rather than the whole. The existing over-generalization in higher education makes teachers confused about the differences between classroom teaching evaluation and curriculum evaluation and misleads the curriculum construction behaviors of front-line teachers.

It is only used to evaluate teaching level of teachers

Theories of teaching evaluation support that: the major function of teaching evaluation is to promote teaching, and identification and selection are just its subsidiary functions. Most colleges and universities will combine evaluation results with teacher position appointment to decide the 
engagement of the teachers. Besides, it brings the identification role of curriculum evaluation into full play. Therefore, teachers may shift their focus on quality requirements of curriculum in theory and practice during practice but alienate it in identification or selection. As a result, curriculum evaluation aimed at identification becomes the basis for teaching practitioners at all levels to explain curriculum evaluation during practice.

\section{Major functions of curriculum evaluation in higher education}

Diagnose the problems in curriculum construction

Curriculum evaluation is an important content of curriculum construction. It helps teacher evaluate the effectiveness and shortcomings of curriculum construction, analyze the successful parts implemented during curriculum construction activities, diagnose the existing problems and causes in curriculum construction and clarify the improvement direction, ways and measures according to the causes by means such as observation, questionnaires, quizzes and so on. By means of curriculum evaluation, it can diagnose existing problems in curriculum construction and correct the bias to help teachers adjust their teaching and research work, better play their advantages and strengths and improve their weaknesses. It can help curriculum construction develop towards the preset goal and realize self-regulation, self-development and self-improvement of teachers ${ }^{[4]}$.

Guide the direction of curriculum construction

In curriculum evaluation, the evaluation of any object will be based on a certain evaluation goal and standard. For the evaluation objects, the evaluation goal, standard, index and weight play the role of "baton" and "compass". Through the curriculum evaluation index system, teachers can learn what schools advocate, encourage and worship during curriculum construction in order to closely relate curriculum construction with the development and positioning of school ${ }^{[5]}$. We can say that the effectiveness of curriculum evaluation index system determines the quality of curriculum construction. Besides, the direction in standards of curriculum evaluation guides the direction of curriculum construction in colleges and universities.

Improve the quality of talent training

Scientific and feasible curriculum evaluation index system and evaluation program with standard practices can inspire the enthusiasm and creativity of teachers in curriculum construction and make curriculum develop towards a healthy direction in order to ensure the achievement of education goals and talent training goals. A comprehensive curriculum evaluation index system can make teachers improve teaching strategies, enrich their knowledge, skills and comprehensive qualities and make them take the initiative to conduct exploratory practice and research of curriculum construction under the guidance of curriculum theories and standards with practical values $^{[6]}$.

\section{Ways and means of curriculum evaluation}

According to the studies and practices of curriculum evaluation in higher education, the author believes that the use of ways and means of curriculum evaluation in higher education should achieve the following combinations:

Combination of formative assessment and summative assessment

The main way of curriculum evaluation is summative assessment for a long time. With the deepening of theoretical research of curriculum evaluation in higher education, people have realized that curriculum implementation always deviates from its objectives due to the impact of internal teaching concepts, abilities and methods of teachers and external teaching resources and conditions during curriculum implementation in higher education. Therefore, people begin to pay more attention to summative assessment based on process evaluation. Certainly, in curriculum evaluation in higher education, the focus on use of formative assessment does not exclude the effective use of summative assessment. They should give priority to process evaluation and combine formative assessment with summative assessment.

Combination of qualitative evaluation and quantitative evaluation 
As it is difficult to measure course objectives, contents and modes, teachers' teaching concepts and students' abilities and qualities by precise quantitative index in course evaluation in higher education, qualitative evaluation still plays a dominant role as the common way in curriculum evaluation. However, in order to ensure the objectivity and equality of curriculum evaluation and improve the efficiency of curriculum evaluation, the quantitative methods such as objective measurement, experimental design and statistical inference are adopted as the necessary means of curriculum implementation and evaluation.

Combination of on-campus evaluation and off-campus evaluation

According to the features of college courses, curriculum implementation is mainly conducted independently by colleges and universities based on the strengths of teachers. However, due to the extensive social relevance, it is necessary to introduce experts in industries and companies to conduct off-campus evaluation in the process of curriculum implementation in order to make curriculum results comply with the needs of economic and social development. Keeping combination of on-campus evaluation and off-campus evaluation is an inevitable choice. The ultimate goal of curriculum reform is to realize the unification of curriculum objectives and talent needs, unification of curriculum content and technological development level and unification of curriculum model and positions. Among them, the evaluation of employers is the ultimate one as the important aspect of quality guarantee system of curriculum in higher education. Therefore, curriculum evaluation should combine its methods, ways and contents and develop the "three links" and "three supervisors" process control mechanism, i.e. strengthen process control in three links of curriculum preparation, implementation and results and establish curriculum evaluation mechanism participated by functional departments, students and experts from industries and companies with the characteristics of higher education ${ }^{[7]}$.

Combination of evaluation feedback and improvement

In curriculum evaluation system in colleges and universities, evaluation feedback is a way to present curriculum evaluation results and the essential part of curriculum evaluation. The question is what the real purpose of curriculum evaluation feedback is and which way is the most reasonable one. Curriculum evaluation feedback is the comprehensive analysis of curriculum design, implementation and results. It provides basis for improving curriculum design, implementation and teaching results. Meanwhile, in terms of feedback attitude and way, the cooperative research method can be adopted. Through the equal communication between the two sides, it can promote the understanding between valuators and those being evaluated and promote self-reflection, thereby developing the integration of evaluation feedback and improvement.

\section{Conclusion}

In a word, curriculum reform of higher education requires Chinese curriculum evaluation activities to start from the specific situation of curriculum reform, develop the curriculum evaluation system with characteristics of the times and provide theoretical support and practical guarantee for current curriculum reform of higher education so that curriculum reform can develop in a healthy way.

\section{References}

[1] Cao Siting. Existing Problems and Countermeasures in Curriculum Quality Evaluation of Higher Education [J]. Journal of Anshun University, 2010 (2).

[2] Wu Lin. Concept Update and System Reform of Curriculum Evaluation of Higher Education [J]. Chinese Higher Education Evaluation, 2005 (2).

[3] Guo Jie. Rational Thinking of Curriculum Development Evaluation of Higher Education [D]. Guangxi Normal University, 2011.

[4] Zhong Jiwen. Teaching Quality Index System and Implications of American Colleges and 
Universities [J]. Modern Distance Education, 2007 (2).

[5] Ma Renting. Rational Analysis of Curriculum Evaluation of Higher Education [J]. Journal of Southern Vocational Education, 2012 (7).

[6] Liang Yangqi. Universities and Colleges Find the Way Out of the Dilemma of Curriculum Evaluation Reform [J]. Research of Higher Education, 2005, (9).

[7] Liu Zhijun. Curriculum Reform and Development Calls for New Curriculum Evaluation [J]. Journal of Tianzhong, 2006, (4). 